\title{
Assessment of self-weight consolidation of flocculated fluid fine tailings under various environmental conditions
}

\author{
B Fisseha University of Alberta, Canada \\ GW Wilson University of Alberta, Canada \\ P Simms Carleton University, Canada
}

\begin{abstract}
Self-weight consolidation properties of polymer-flocculated fluid fine tailings (FFT) have been investigated in a laboratory using a meso-scale column apparatus with dimensions of $300 \mathrm{~mm}$ (diameter) by $1.8 \mathrm{~m}$ (height). Four meso-scale columns were used to carry out self-weight consolidation of flocculated FFT with flocculant dosages of $650 \mathrm{~g} / \mathrm{L}$ (one column) and $850 \mathrm{~g} / \mathrm{L}$ (three columns). The laboratory investigation attempts to mimic set-ups of the meso-scale consolidation columns under various environmental considerations such as with no evaporation (one column of $850 \mathrm{~g} / \mathrm{L}$ dosage), with evaporation only (one column of $650 \mathrm{~g} / \mathrm{L}$ and one column of $850 \mathrm{~g} / \mathrm{L}$ dosage), and with evaporation and decantation (one column of $850 \mathrm{~g} / \mathrm{L}$ dosage). The laboratory investigation enables the characterisation of self-weight consolidation of flocculated FFT, using the relationship between the total settlement of deposited tailings versus measured excess pore water pressure dissipation and expected hydrostatic line for various flocculant dosages and environmental considerations. The measured data will be used to assess and verify the self-weight consolidation properties with respect to the principles of soil mechanics.
\end{abstract}

Keywords: inline flocculation of tailings, fluid fine tailings, self-weight consolidation

\section{Introduction}

The oil sands industry in northern Alberta, Canada, faces enormous challenges in managing generated tailings, the by-products of mining and mineral processing. Tailings are composed of sand, fines (silt and clay-size materials) and bitumen. These tailings have slow settling rates and low hydraulic conductivity due to their composition, which is dominated by fines. These high fines contents increase in significance during extraction processes due to the addition of dispersing agents (Beier et al. 2009). Upon deposition, the tailings segregate with the coarser sands to form beaches and dykes, with the fines and bitumen materials being stored in ponds (i.e. fluid fine tailings, FFT). Sedimentation occurs in the ponds and within two to three years the solids content reaches $30-35 \%$. These deposits have properties that are slow to consolidate. Once the process of sedimentation ceases, the process of self-weight compression governs the specified solids content. Mine operators are currently using containments to store FFT. The containments create large surficial footprints and, to date, have proven to present an engineering challenge to reclaim.

Multiple research initiatives are being undertaken by a number of mine operators in order to increase the dewaterability and subsequently accelerate the trafficability of the deposited tailings. Some of the research initiatives under consideration are: (i) composite tailings, (ii) conventional thickening, (iii) centrifugation, (iv) inline flocculation and thickening along with ( $v$ ) various combinations of the mentioned techniques. Thin-lift deposition and/or other dewatering techniques have also been given consideration. These research initiatives increase dewatering of deposited tailings through desiccation (i.e. evaporation, drainage and/or freeze-thaw) and consolidation (Morgenstern \& Scott 1995).

Polymer-amended or polymer-flocculated fine tailings, using inline injection of polymer some distance from the deposition point, has been employed at the commercial scale by Suncor and Shell (Matthews et al. 2011; Wells 2011). Initially, this approach was used in conjunction with thin-lift deposition, and most of the dewatering was 
thought to occur from initial application of the polymer (flocculation and sedimentation/consolidation over one or two days) and from subsequent evaporation over weeks and months. Lately, interest has grown in the use of flocculated FFT in deeper deposits to take advantage of potential improvements in consolidation behaviour due to the flocculation process.

Various academic research projects (Jeeravipoolvarn et al. 2010; Qi et al. 2017b; Rozina et al. 2015; Soleimani et al. 2014) and field trials (Dunmola et al. 2014) have indicated that flocculated FFT consolidation behaviour is superior to that of raw FFT, at least up to some critical stress level. It is well understood and established that geotechnical engineering problems, such as high-volume change deposits (consolidation), stability of earthfill structures, and reclamation of tailings impoundments can best be analysed using fundamental principles of soil mechanics for both saturated and unsaturated soils. For example, unsaturated flow behaviour has been used to predict the dewaterability of thin and/or multilayer tailings deposits of high-density hard rock tailings as well as evaporation and drainage of tailings (Fisseha et al. 2010; Qi et al. 2016, 2017a, 2017b; Salfate et al. 2010; Simms et al. 2007, 2010, 2017). Large-strain consolidation properties and shear strength development for treated FFT was investigated under stress-controlled conditions (Fisseha et al. 2017). Establishing constitutive relations for deposited FFT or materials can be used along with the fundamentals of soil mechanics in both saturated and unsaturated conditions. It is important to have measured laboratory material properties for verification purposes.

This paper will present results obtained from meso-scale laboratory tests (1.8 $\mathrm{m}$ high columns) on the self-weight consolidation of polymer-flocculated FFT. These tests provide an important dataset to calibrate and improve numerical models used for simulating FFT properties measured during self-weight consolidation. Furthermore, it can be incorporated for the improvement and modification of numerical models that can analyse and accurately compute the flow properties of deposited flocculated FFT.

\section{$2 \quad$ Methodology}

Fluid fine tailings characterisation was carried out to determine the required optimum flocculant dosage, to obtain geotechnical index properties and engineering properties of flocculated FFT during the self-weight consolidation process for the meso-scale trial. Descriptions of the laboratory tests are presented.

\subsection{Material preparation and characterisation test}

The preparation of FFT from homogenisation to the inline flocculation process was carried out at the Oil Sands Tailings Research Facility (OSTRF). The geotechnical index and standard engineering properties were evaluated using the homogenised and flocculated FFT at the University of Alberta. The meso-scale column test for the self-weight consolidation characterisation was carried out at the OSTRF. The general layout of the OSTRF facility and available equipment are presented in Figure 1. Details of the facility's set-up and available equipment can be found on the website (www.ostrf.com/facility).

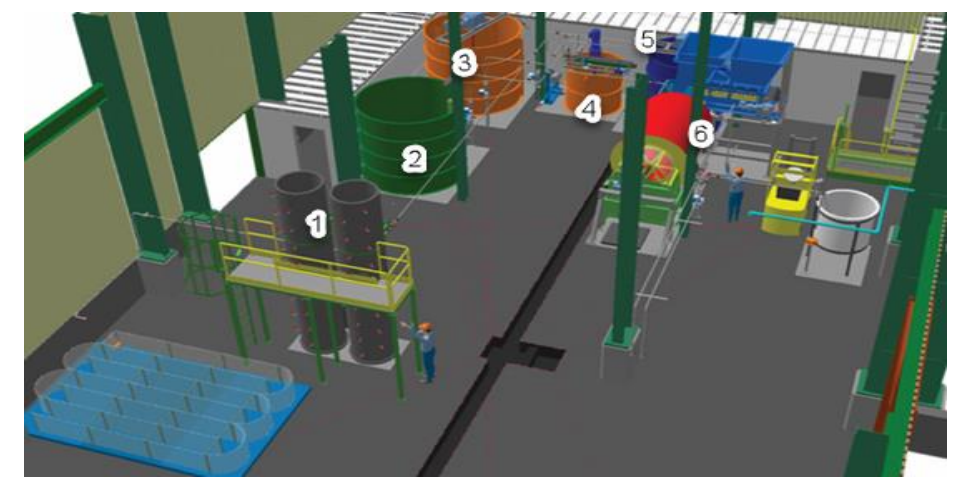

Figure 1 General layout of OSTRF facility set-up. The equipment displayed is 1 . Settling columns; 2. Total tails (TT) tank; 3. Composite tails (CT) tank; 4. Composite tailings with agitator tank; 5. Fine tails (FT) tank; and, 6. Tumbler (taken from Oil Sands Tailings Research Facility 2017) 
Homogenisation of FFT was completed by pumping FFT, which was shipped from the mine site, into a composite tailings (CT) tank. Pumped FFT was allowed to homogenise by mixing thoroughly using an agitator, which is situated within the CT tank. The homogenised FFT was prepared to have a solids content of $35.5 \%$ to mimic commercial scale conditions.

\subsection{Geotechnical index properties and settling test}

The geotechnical index properties and settling rate of flocculated FFT were tested to characterise fundamental properties of flocculated FFT and to determine required optimum flocculant dosage. Column settling and yield stress testing were carried out using a graduated column and rheometer with controlled shear rate, respectively. A number of trials were conducted by varying the flocculant dose in order to determine the optimum dosage.

In addition, the following geotechnical index tests were carried out to characterise the FFT: grain size analysis, Atterberg limit (i.e. liquid limit (LL), and plastic limit (PL)), specific gravity (SG) and bitumen content.

A standard settling test was conducted by pouring flocculated FFT into a 1,000 mL standard graduated cylinder (34.5 cm high). The change in volume (i.e. change in vertical strain) was monitored as the deposited material progressed with the settling test process. The graduated cylinder was sealed using a rubber stopper to prevent the possible effect of evaporation. As the deposited material settled down, bleed water was collected on top of the settled tailings within the cylinder. Determination of the optimum flocculant dose was carried out by comparing settlement of FFT mixed with different flocculant doses.

\subsection{Standard engineering property test}

A number of standard laboratory tests were carried out to characterise and obtain the engineering properties of flocculated FFT. A brief description of the testing procedures is presented herein.

\subsubsection{Compressibility property test using standard large-strain consolidation testing apparatus}

A multi-step loading consolidometer apparatus (100 mm diameter $\times 150 \mathrm{~mm}$ height) was used to carry out large-strain consolidation (LSC) testing. Flocculated FFT poured into the LSC apparatus was left to complete its self-weight consolidation process. Subsequently, an incremental surcharge load was applied to the placed FFT using a dead load (up to $5 \mathrm{kPa}$ ) and a loading frame by an air pressure bellofram (over $10 \mathrm{kPa}$ ). The pressure transducer situated at the base of the LSC apparatus was used to monitor the change in excess pore pressure generated due to applied loads. A linear vertical displacement transducer (LVDT) was attached to monitor the change in height of the placed materials.

Once each incremental load was applied, the progress of consolidation was evaluated by monitoring the change in height of the placed sample and the dissipation of excess pore pressure with time. Plots of height versus time and excess pore pressure versus time were generated once each applied load was completed. Subsequently, plots of effective stress versus void ratio (known as compressibility curves) were obtained for the flocculated FFT.

\subsubsection{Hydraulic conductivity property test using standard large-strain consolidation testing apparatus}

The hydraulic conductivity of flocculated FFT was measured once the process of consolidation for each applied load was completed. A constant head test was conducted using an upward flow set-up that passed through the placed FFT specimen. The hydraulic gradient used during the characterisation test ranges between 0.3 and 0.6 . Plots of hydraulic conductivity versus void ratio were generated following the completion of the hydraulic conductivity test for each applied incremental load. 


\section{Meso-scale self-weight consolidation test}

The meso-scale experiment was designed to determine the self-weight consolidation properties of inline flocculated FFT using a column apparatus with dimensions of $30 \mathrm{~cm}$ by $1.8 \mathrm{~m}$ (diameter by height). Details of the column apparatus design and description are presented in the following sections.

\subsection{Design of meso-scale column apparatus and instrumentation}

A Plexiglas column apparatus was prepared for the self-weight consolidation testing. The column was designed to have a complete seal at the bottom and the deposited flocculated tailings were left to consolidate under self-weight. Four separate columns were arranged to carry out the meso-scale self-weight consolidation laboratory testing under different environmental considerations as described in Section 3.3.

The columns were instrumented with a number of sensors in order to monitor the change in the deposited materials. These sensors are positive and negative pore water pressure measuring sensors. The reference datum was assumed to be at the base of the column (i.e. base $=0 \mathrm{~mm}$ height). The change in total settlement (vertical strain) was monitored using a stationary camera by capturing photos of the consolidation test column at specified time intervals.

\subsection{Laboratory set-up of the meso-scale column testing}

The meso-scale column set-up was used to carry out the self-weight consolidation test of flocculated FFT. The set-up comprises a CT tank, floc solution tank, static mixer, pumps (regular and peristaltic), Plexiglas columns, rubber hose and fittings as connecting adaptors. Three separate static mixers were coupled in series to provide sufficient mixing between the floc solution and tailings. The static mixer was connected to the CT tank and floc solution tank through an extended hose at one end. A regular pump was used to push the flow of homogenised tailings from the CT tank at a regulated flow rate. The flow and mixing rate of the FFT at the CT tank were controlled using a computerised system, which was connected to the regular pump. Similarly, the peristaltic pump was used to pump required floc solution by injecting into the static mixer at the designed flow rate. The flow rate of the injected floc solution was controlled using the built-in input dialogue configuration system on the peristaltic pump. The meso-scale self-weight consolidation test set-up is presented in Figure 2.
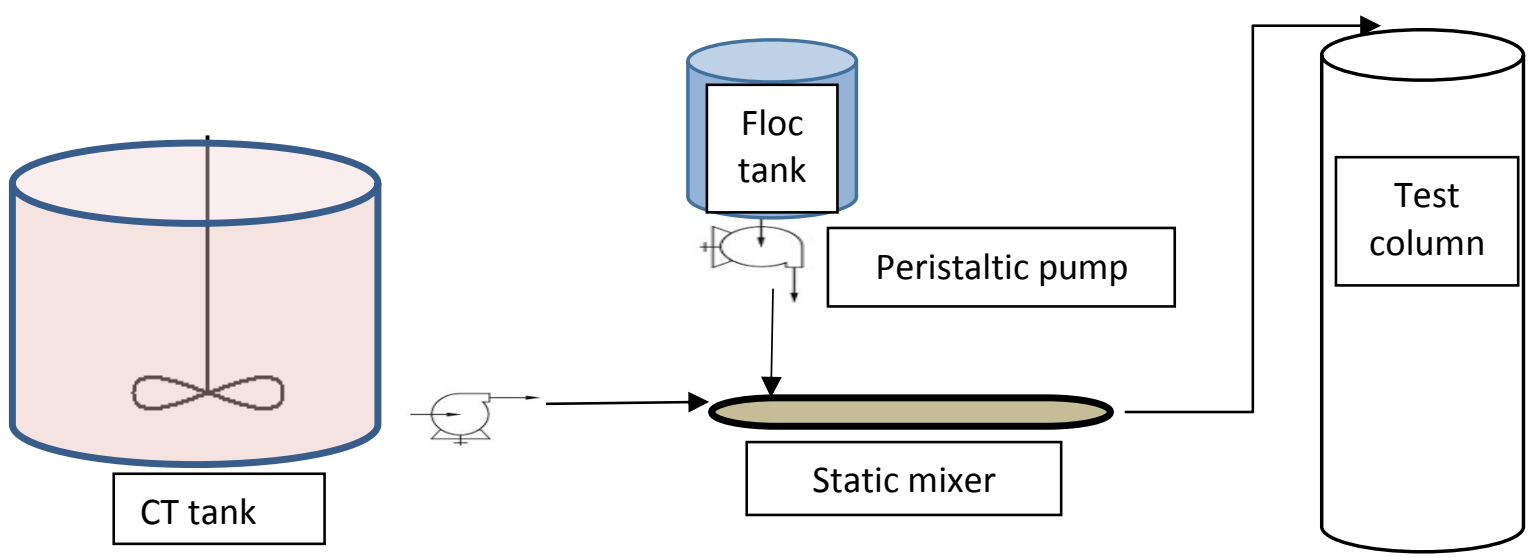

Figure 2 Schematics of inline flocculation of FFT and deposition of column tests

A rubber hose line of $5.08 \mathrm{~cm}$ diameter was connected from the regular pump to the static mixer. The hose line was used to transport the FFT from the CT tank into the static mixer. A polyethylene tube of $2.54 \mathrm{~cm}$ diameter was used to channel the floc solution to the static mixer. The two lines (line 1 - the rubber hose from the $\mathrm{CT}$ tank to the static mixer, and line 2 - polyethylene tube from floc solution tank to the static mixer) were connected into one end of the static mixer using a T-shaped coupler/connector. The FFT and floc 
solution were thoroughly mixed while flowing through the static mixer, and emerged as inline flocculated FFT, on the other end of the static mixer. Injected floc dosages were adjusted as needed (designed) during the inline flocculation mixing through regulating the pumping rates. Freshly flocculated tailings were deposited into the column apparatus for the self-weight consolidation test.

\subsection{Design considerations of the meso-scale column testing}

Each column was designed to simulate a specified field or environmental condition. The following field or environmental conditions were considered during the self-weight consolidation test: (i) evaporation was not allowed by sealing the column at the open end (labelled as Column 1), (ii) evaporation and decantation were allowed by exposing one end of the column to the environment and manually removing accumulated bleed water from the column (Column 2), and (iii) evaporation only was considered by exposing the column to the environment (Columns 3 and 4). Column 4 was used as a duplicate test. Table 1 summarises the testing considerations and floc doses used during the meso-scale self-weight consolidation test.

Table 1 Summary of design considerations for the meso-scale self-weight consolidation tests

\begin{tabular}{|c|c|c|c|c|c|}
\hline Description & $\begin{array}{l}\text { Used floc } \\
\text { dosage } \\
\text { (ppm) }\end{array}$ & $\begin{array}{l}\text { Testing } \\
\text { consideration }\end{array}$ & $\begin{array}{l}\text { Material } \\
\text { type }\end{array}$ & $\begin{array}{l}\text { Evaporation } \\
\text { rate }(\mathrm{mm} / \text { day })\end{array}$ & $\begin{array}{l}\text { Period the self-weight } \\
\text { consolidation carried } \\
\text { out (days) }\end{array}$ \\
\hline Column 1 & 850 & No evaporation & 1 & 0 & 600 \\
\hline Column 2 & 850 & $\begin{array}{l}\text { Evaporation and } \\
\text { decantation }\end{array}$ & 1 & 2.08 & 600 \\
\hline Column 3 & 650 & Evaporation only & 2 & 1.84 & 350 \\
\hline Column 4 & 850 & Evaporation only & 2 & 1.63 & 350 \\
\hline
\end{tabular}

Table 2 presents a summary of pore water pressure measuring sensor types and associated locations within a given column apparatus.

Table 2 Elevations of negative and positive pore water pressure measuring sensors placed in the column

\begin{tabular}{lllllll}
\hline & \multicolumn{4}{l}{ T5 tensiometer (positive and } & \multicolumn{4}{l}{ GK pore pressure sensors (positive pore water } \\
Column ID & negative pore water pressures) (cm) & \multicolumn{2}{l}{ pressure only) measuring sensor position (cm) } \\
& T51 & T52 & GK1 & GK2 & GK3 & GK4 \\
\hline 1 & Tailings and water interface & 99.5 & - & - & - & - \\
2 & 40 & 90 & - & - & - & - \\
3 & 40 & 92 & - & - & - & - \\
4 & - & - & 16 & 41 & 91 & 116 \\
\hline
\end{tabular}




\section{$4 \quad$ Results and discussion}

The geotechnical index properties, engineering properties and results of the meso-scale consolidation tests of the flocculated FFT are presented in the following sections.

\subsection{Geotechnical index properties, settling rate and yield stress}

Geotechnical index properties and settling rate results are summarised and presented in the following sections.

\subsubsection{Index properties}

The summary of index properties are presented in Table 3.

Table 3 Summary of geotechnical index properties of FFT

\begin{tabular}{lll}
\hline Characteristics & Material 1 & Material 2 \\
\hline Methyl Blue Index (meq/100 g) & 5.58 & 3.75 \\
Bitumen content (\%) & 3.8 & 2.57 \\
D $_{10}, D_{50}, D_{60}$ (microns) & $0.8,6.4,11.1$ & - \\
Specific gravity & 2.2 & 2.22 \\
Liquid limit (\%) & 62 & 42 \\
Plastic limit (\%) & 26.7 & 30 \\
Fines content $(<44 \mu \mathrm{m})(\%)$ & 78.7 & 40 \\
\hline
\end{tabular}

Figure 3 presents plots of the particle size distribution of the fluid fine tailings under investigation. The composition of FFT is dominated by fines, which is between 77 and $79 \%$ fines (i.e. $<44$ microns) for Material 1 as presented in Table 3 and Figure 3, respectively. A particle size analysis for Material 2 was generated using software by only using measured boundary values such as clay, silt and sand contents only. Overall, Material 2 was composed of coarser particle sizes compared to Material 1. The fines content for Material 2 shows $\sim 40 \%$.

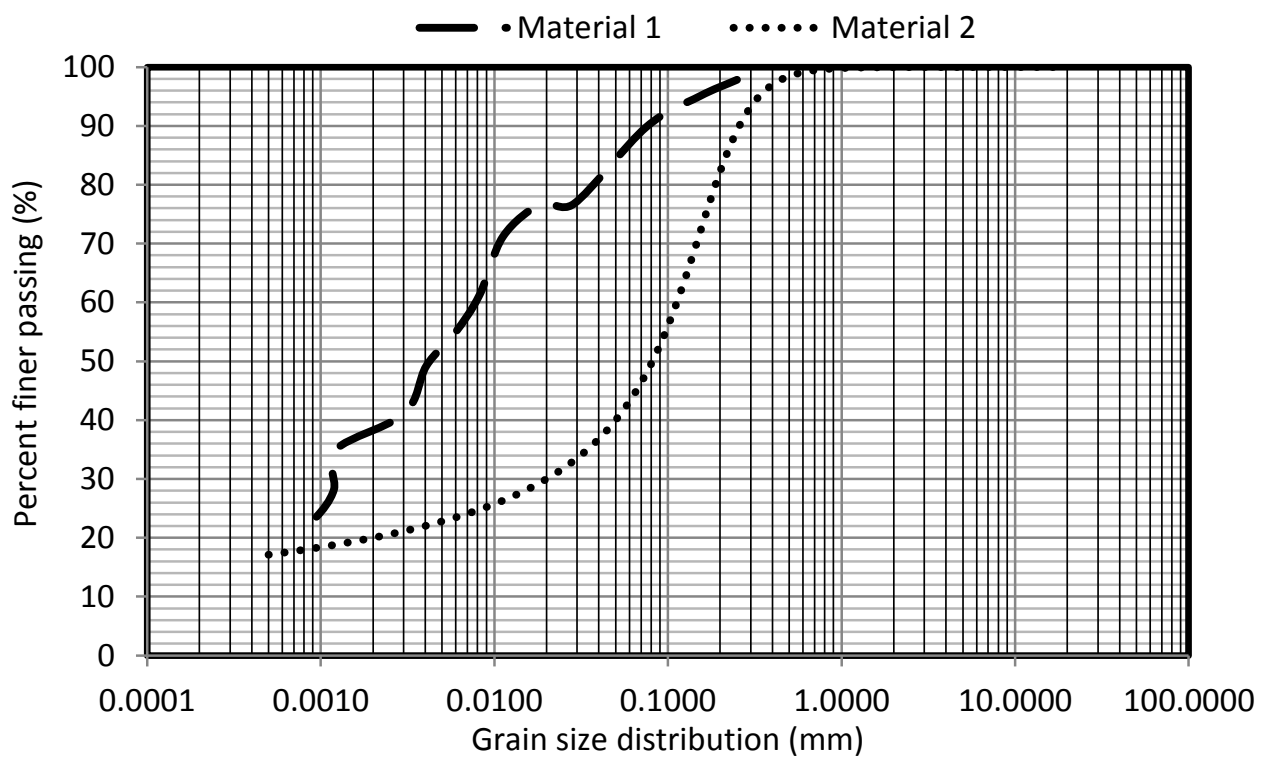

Figure 3 Particle size distribution of the FFT 


\subsubsection{Settling rate and yield stress}

Figure 4 presents the settling test results of flocculated FFT Material 1 using different doses of the anionic flocculant once the self-weight consolidation process is completed. Results show that an initial deposit of flocculated FFT starts at an initial void ratio of 4.1 and attains a final void ratio of 3.31 for the $850 \mathrm{ppm}$ flocculant dosage. Similarly, an initial deposit of flocculated FFT begins at an initial void ratio of 4.15 and reaches a final void ratio of 2.99 for the $650 \mathrm{ppm}$ flocculant dosage.

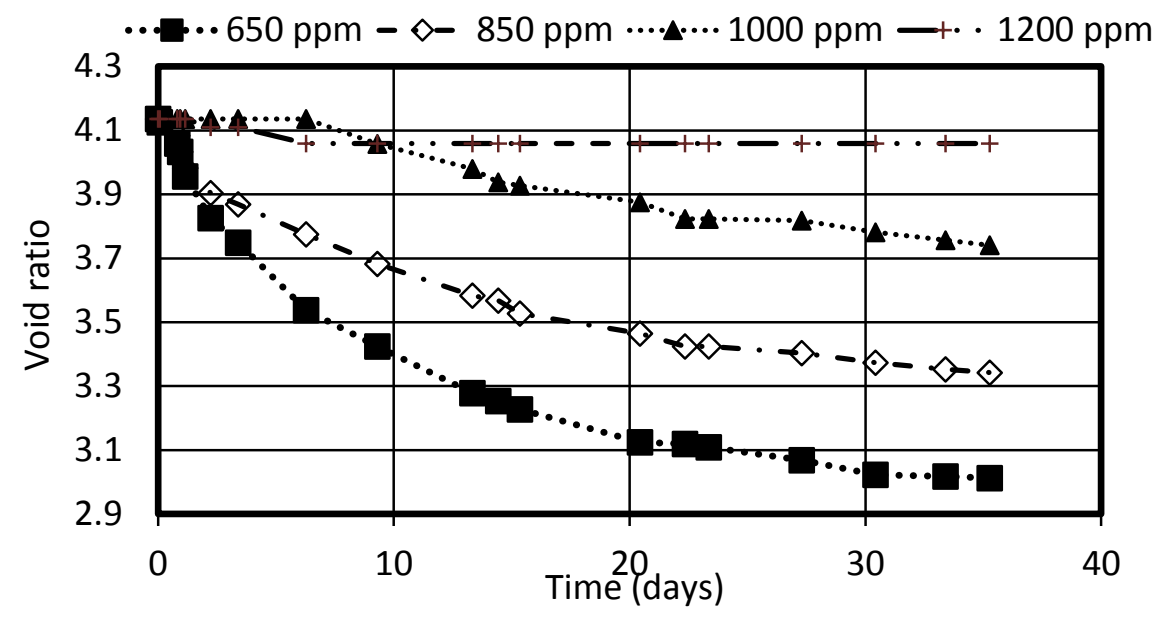

Figure 4 Settling test results of flocculated FFT Material 1

Based on the column settling test results (presented in Figure 4) and measured yield stress values of various flocculant doses from laboratory and field trails (presented in Figure 5), the optimum flocculant dosage was determined to be $850 \mathrm{ppm}$ (Mizani 2017). Therefore, a $850 \mathrm{ppm}$ floc dosage was used to prepare the flocculated tailings for the meso-scale self-weight consolidation column test to be consistent with the previously carried out laboratory flume test experiment (Mizani et al. 2013) and field-scale tests (Dunmonla et al. 2014). In addition, one of the self-weight consolidation column tests used a $650 \mathrm{ppm}$ floc dosage to investigate variation in floc dosages. Results of the self-weight consolidation tests are presented in the following section.

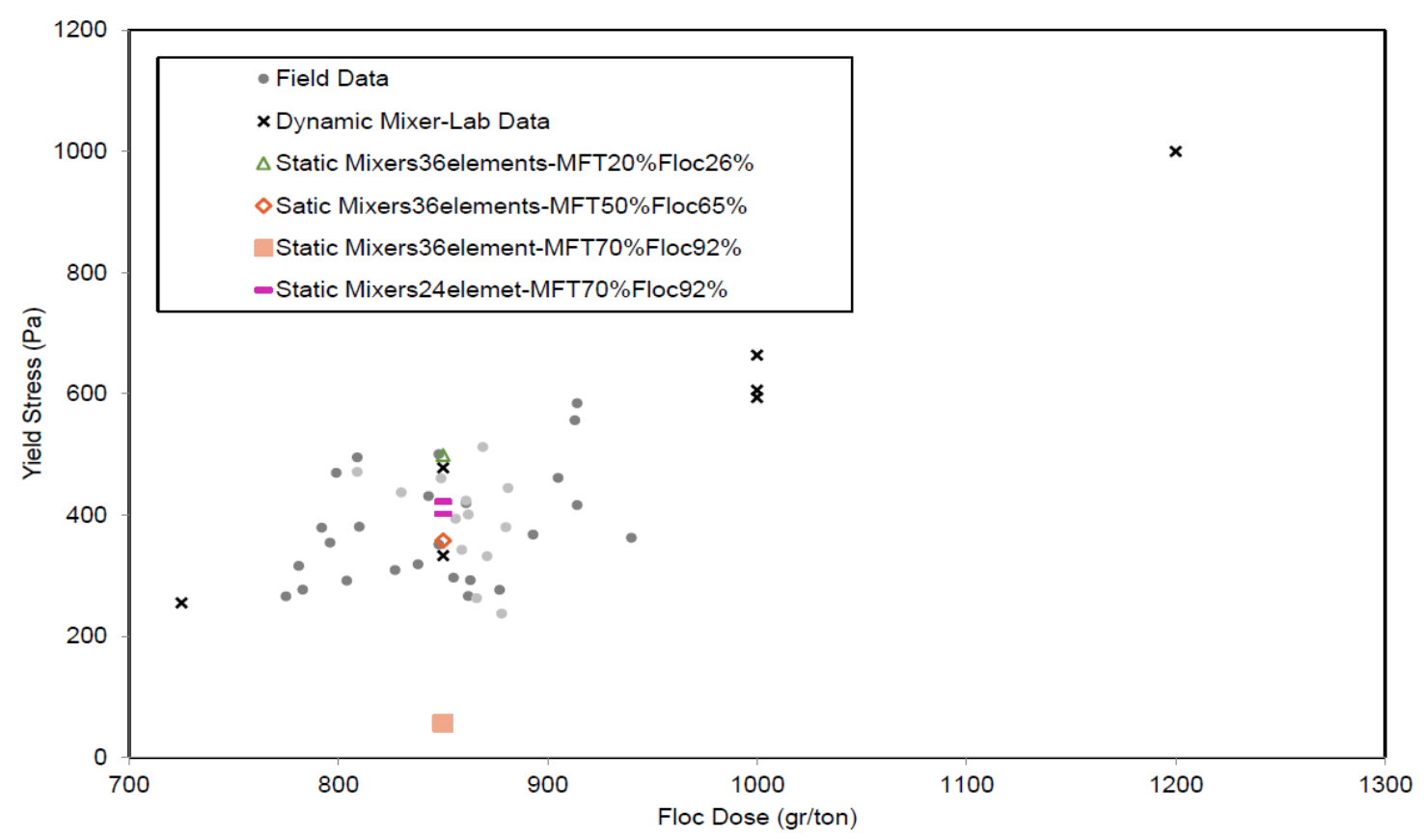

Figure 5 Yield stress values for various flocculant dosages and pump mixing set-ups (adapted from Mizani 2017) 


\subsection{Engineering properties}

Measured engineering properties of flocculated FFT for both Materials 1 and 2 are presented in the following section.

\subsubsection{Compressibility curve}

Figure 6 presents the relationship between effective stress and void ratio for the flocculated FFT using different floc dosages. The tailings exhibited a decreasing trend in void ratio as a function of effective stress. Power law equations were found to best describe the volume compressibility behaviour of the investigated flocculated FFT. In general, obtained results of different flocculant doses show similar compressibility behaviour during the characterisation of each test of the given FFT. Results of compressibility for the flocculated FFT displays reduced void ratio at the lower effective stress values compared to the raw FFT. In general, measured compressibility curves are consistent with results stated in literature.

850 ppm • 1000 ppm $\Delta 1200$ ppm $\bullet 1500$ ppm * Raw FFT (Pollock 1988)

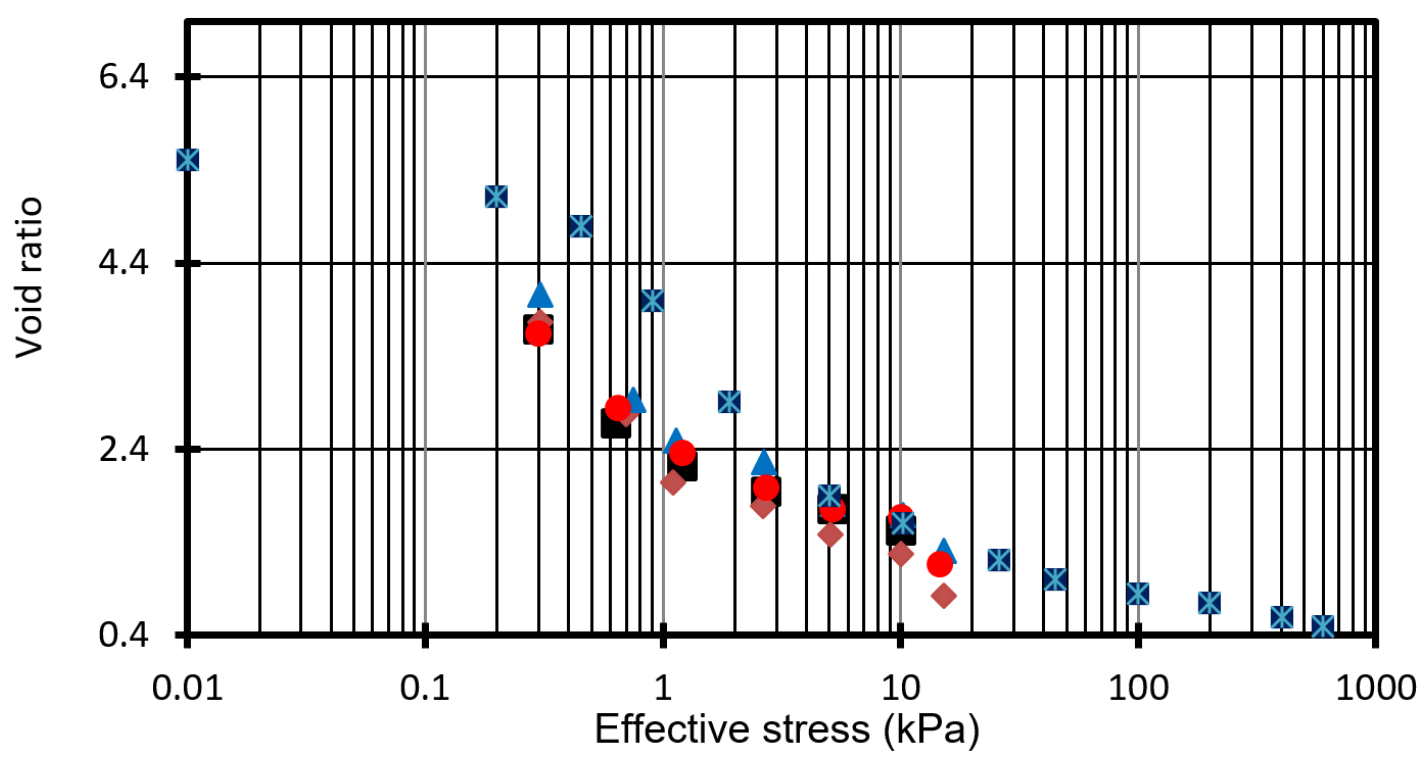

Figure 6 Compressibility curves of flocculated FFT measured using standard LSC tests (raw FFT from Pollock 1988)

\subsubsection{Hydraulic conductivity curve}

Figure 7 presents the void ratio versus hydraulic conductivity results for the flocculated FFT using different flocculant dosages. In general, results of different flocculant doses show similar hydraulic conductivity behaviour during the characterisation of tests of hydraulic conductivity curves on the given FFT. An increasing power law function is exhibited and about four orders of magnitude difference in hydraulic conductivity is shown between the highest and lowest measured void ratios. Results of hydraulic conductivity for the flocculated FFT displays higher hydraulic conductivity at the higher void ratio values compared to the raw FFT. In general, measured hydraulic conductivity functions are consistent with results stated in literature. 
— 850 ppm • 1000 ppm $\Delta 1200$ ppm 1500 ppm * Raw FFT (Pollock 1988)

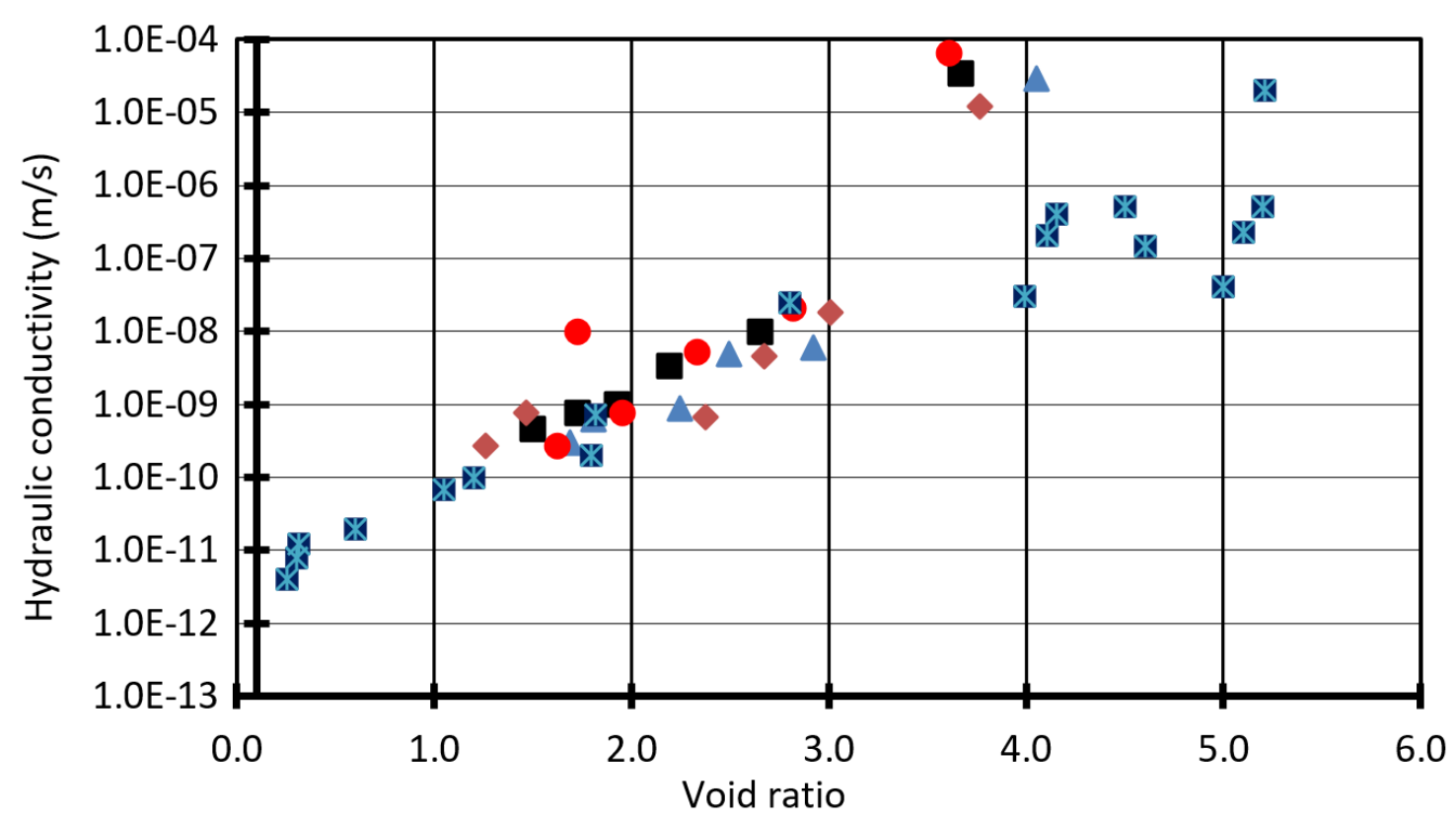

Figure 7 Hydraulic conductivity curve of flocculated FFT measured using a standard LSC testing cell (raw FFT from Pollock 1988)

\subsection{Meso-scale self-weight consolidation results}

The results for the meso-scale self-weight consolidation testing are presented in the following section. These results include measured sedimentation/settlement of the deposited FFT and excess pore water pressure dissipation.

\subsubsection{Settlement}

Column 1 - no evaporation condition: Figure 8 presents the total settlement of deposited tailings within Column 1. Tailings deposited within Column 1 settled with a sharper slope at its initial stage (until day 20), followed by a gentler settlement (until day 104), and finally with flatter slope (infinitesimal change) from day 225 to the end of the test. Overall, the tailings deposited within Column 1 settled a total height of $609 \mathrm{~mm}$.

Column 2 - with evaporation and decantation: Figure 8 presents total settlement of deposited tailings within Column 2. Tailings within Column 2 settled with a steeper slope at its initial stage (until day 255), followed by moderate slope settlement (until day 410), and finally with much more sluggish slope from day 410 until the end of the test. Overall, the tailings within Column 2 settled a total height of $785 \mathrm{~mm}$.

The cause for the difference in settling rate between Columns 1 and 2 will be investigated further during the decommissioning process, since the deposited tailings within the two columns were prepared as one batch. Evidently, the effects of the evaporation and the decantation process contributed towards the total settlement in Column 2, due to developed negative water pressure (suction) by day 410 . The consolidated tailings exhibited lateral compression and pulled away from the column wall boundary. The consolidated and contracted tailings had a final diameter of $23 \mathrm{~cm}$ compared to its initial diameter of $30 \mathrm{~cm}$.

Columns 3 and 4 - with evaporation only: Figure 8 presents total settlement of deposited tailings within Columns 3 and 4. Tailings within Columns 3 and 4 settled with identical slope, that is with sharper slope at its initial stage (until day 27), followed by gentler slope settlement (until day 124), and finally with sluggish slope (from day 124 to the end of the test). Overall, the tailings within Columns 3 and 4 settled a total height of $853 \mathrm{~mm}$. Settlement results of Columns 3 and 4 indicate that there is no effect of flocculant dosage between the deposited tailings within the two columns. 


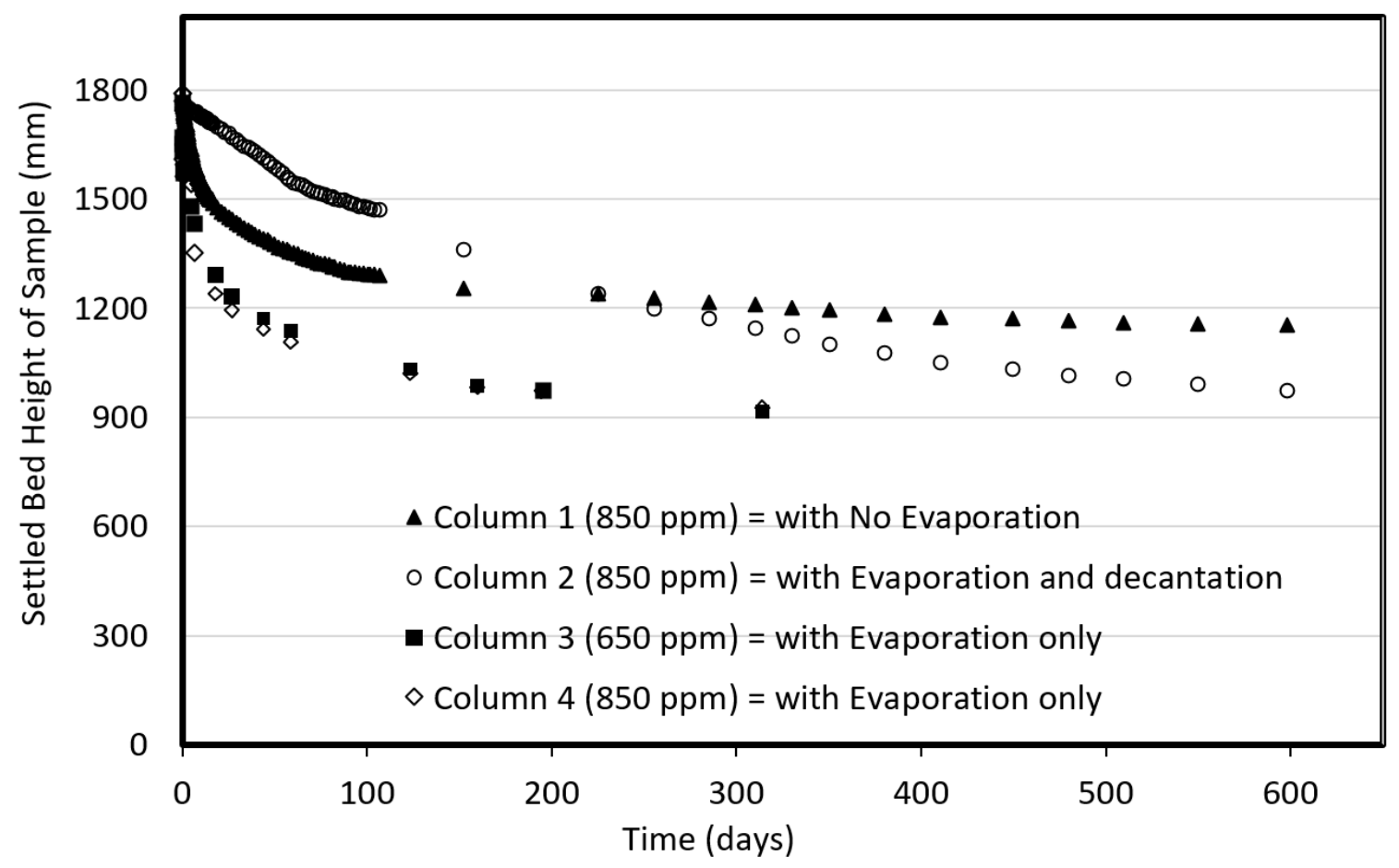

Figure 8 Settlement of inline flocculated FFT during the meso-scale self-weight consolidation test

Furthermore, the cause for the exhibited settling rate and total settlement differences between Columns 1 , 2, 3 and 4 will be investigated and analysed once additional results are collected during the decommissioning process. In general, the difference between Material 1 settlement (Columns 1 and 2) and Material 2 settlement (Columns 3 and 4 ) is attributed to the coarser particle sizes present within Material 2. Material 2 settled at a much steeper slope compared to Material 1 during the initial stage of sedimentation as shown in Columns 3 and 4.

\subsubsection{Excess pore water pressure dissipation}

The measured total pore water pressure (PWP) and expected hydrostatic PWP for the meso-scale columns are presented in the following section.

Column 1 - no evaporation condition: Total PWP measurements of Column 1 are presented in Figure 9. Measured total PWP and expected hydrostatic PWP for the sensors located at the interface of tailings and water line and $99 \mathrm{~cm}$ above the base are presented in Figure 9. Excess PWP is the difference between the measured total PWP and expected hydrostatic PWP line. Excess PWP was fully dissipated by day 177 for the sensor located at the interface and by day 240 for the sensor located $99 \mathrm{~cm}$ above the base of the column. Measured PWP matches with the expected hydrostatic line from day 300 until end of the test (day 600), which is consistent with the scenario (i.e. no evaporation allowed). The sensor located at the interface between tailings and water line only measured during the first 200 days of the test. Once the sensor started measuring the hydrostatic PWP, it was disconnected and removed for other purposes. 


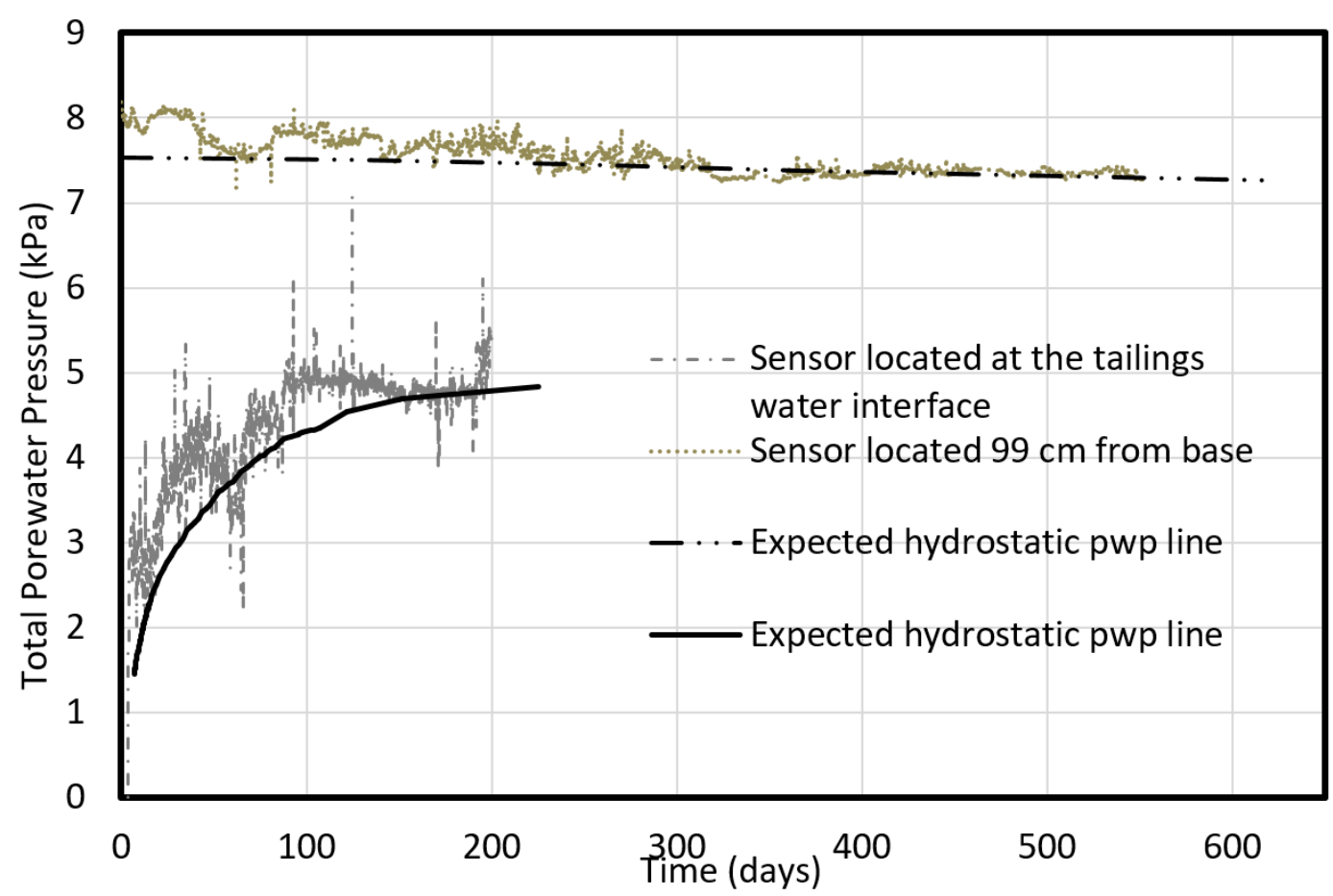

Figure 9 Measured total and expected hydrostatic pore water pressures of deposited flocculated FFT during the self-weight consolidation test for the meso-scale Column 1

Column 2 - with evaporation and decantation: Total PWP measurements of Column 2 are presented in Figure 10. Measured total PWP and expected hydrostatic PWP for the sensors located 92 and $40 \mathrm{~cm}$ above the base are presented in Figure 10. Excess PWP was fully dissipated by day 180 for the sensor located at $92 \mathrm{~cm}$ and day 255 for the sensor located $40 \mathrm{~cm}$ above the base of the column. Figure 10 shows steeper descending excess PWP dissipation and expected hydrostatic line slope between days 0 to 70 . The steepness of the slope, particularly the descending stair-like arrangement from until day 70 , was due to periodic removal of bleed water (decantation) from the surface of the tailings.

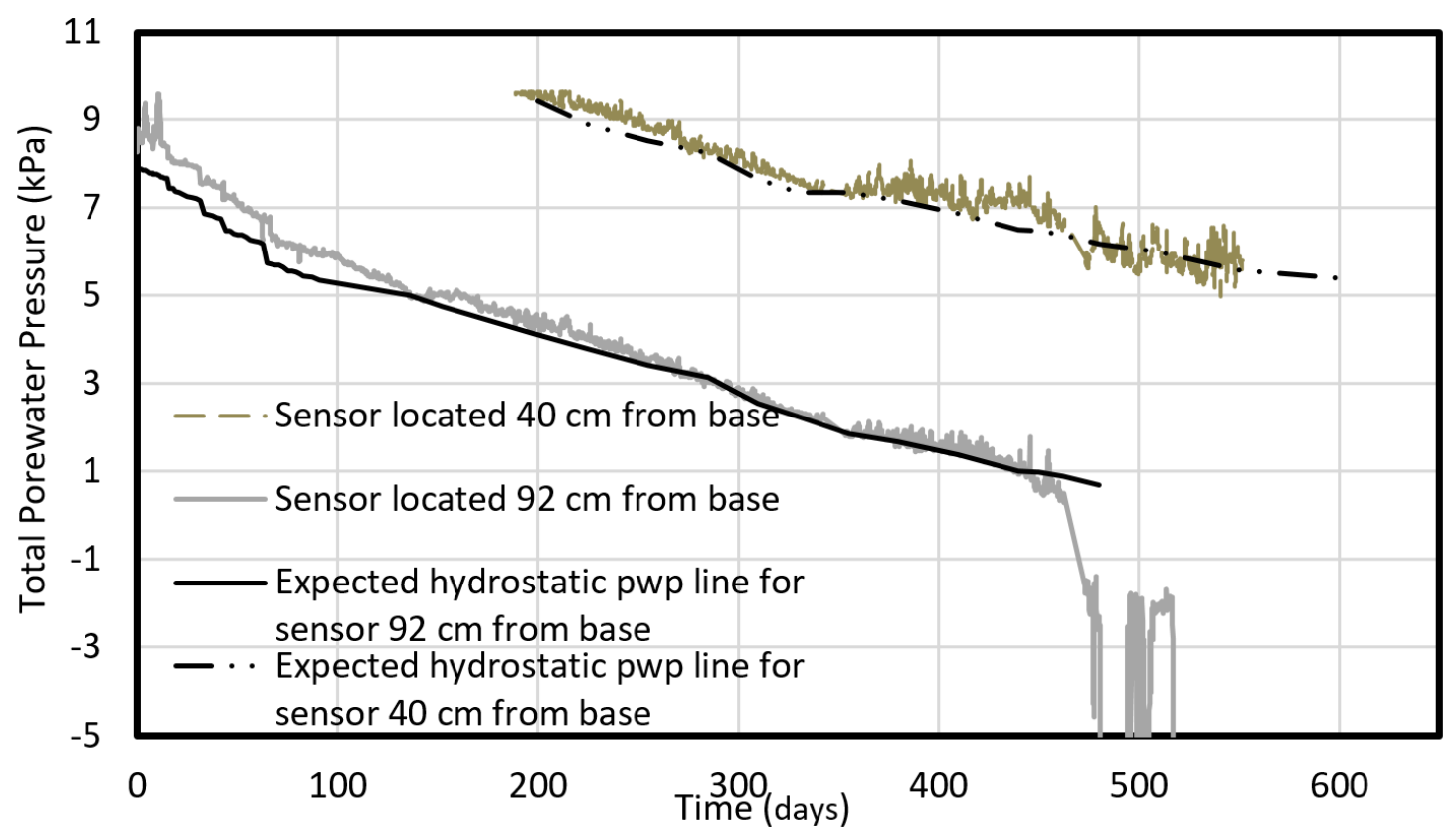

Figure 10 Measured total and expected hydrostatic pore water pressures of deposited flocculated FFT during the self-weight consolidation test for the meso-scale Column 2 
Overall, the effect of evaporation and decantation accelerates excess PWP dissipation for Column 2 compared to Columns 1 and 3 . In addition, the sensor located at $92 \mathrm{~cm}$ measured negative water pressure (suction) starting on day 465 as the level of water dropped below the tailings surface. The maximum measured suction was $-163 \mathrm{kPa}$ on day 485 . The sensor located close to the tailings surface cavitates as the negative PWP measurement became larger. The sensor located $40 \mathrm{~cm}$ above the base failed to respond for the first 188 days of the meso-scale test, and began reading thereafter as presented in Figure 10.

Column 3 - with evaporation only: Total PWP measurements of Column 3 are presented in Figure 11. Measured total PWP and expected hydrostatic PWP for the sensor located $90 \mathrm{~cm}$ above the base are presented in Figure 11. Excess PWP was fully dissipated by day 200. The hydrostatic PWP line was measured after day 200. The sensor located $40 \mathrm{~cm}$ above the base of the column was not responding well.

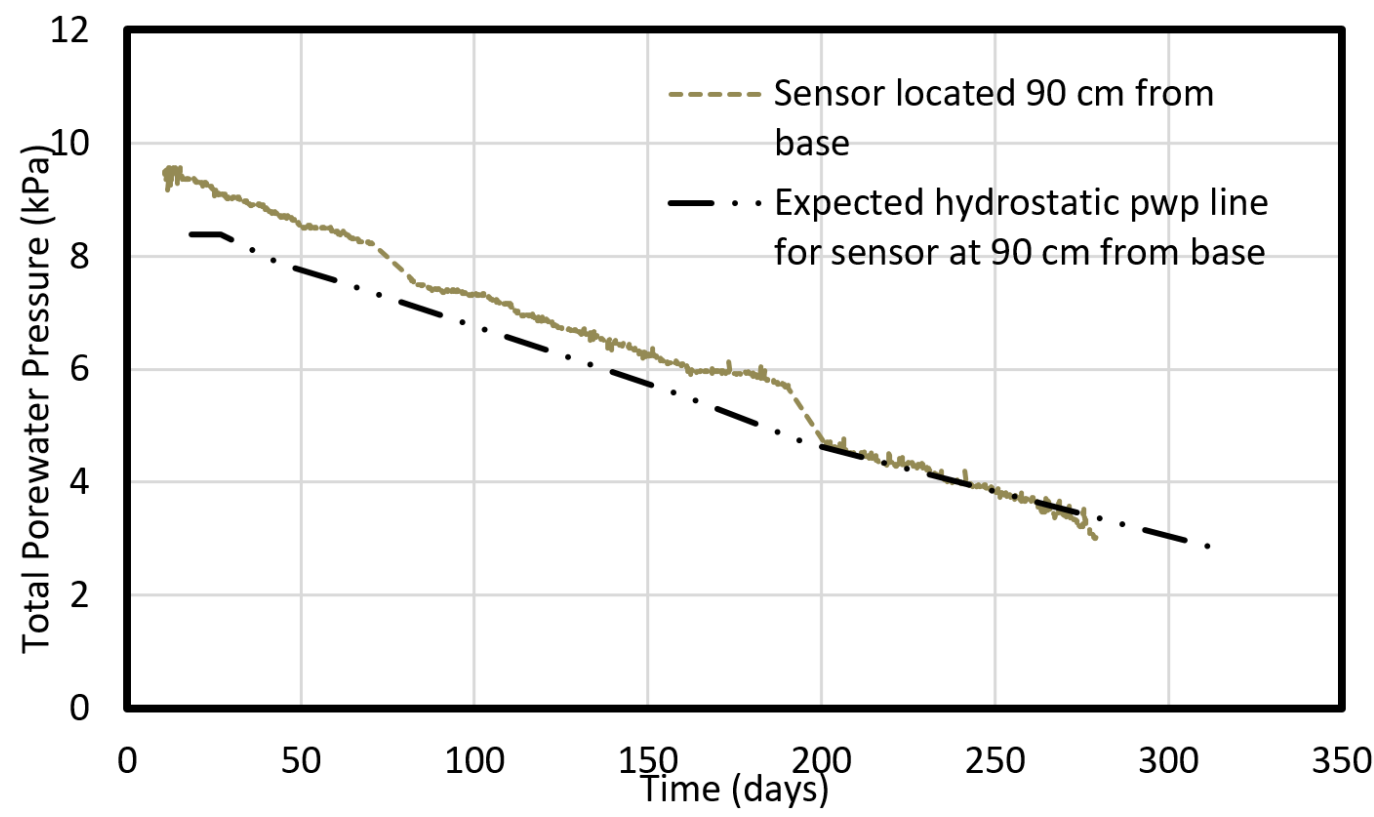

Figure 11 Measured total and expected hydrostatic pore water pressures of deposited flocculated FFT during the self-weight consolidation test for the meso-scale Column 3

Column 4 - with evaporation only: Measurements of total PWP using the positive pore water pressure measuring sensors are not presented here since the collected results showed irregular values compared to the expected total pore water pressure values. The reason for the irregularity is possibly due to the induced excitation from the wiring of the sensors with the power source. Therefore, the results are not presented here.

Figure 12 presents a photo of dried, contracted and consolidated FFT around the surface of the deposited tailings from Column 2 with evaporation and decantation scenario by day 600 .

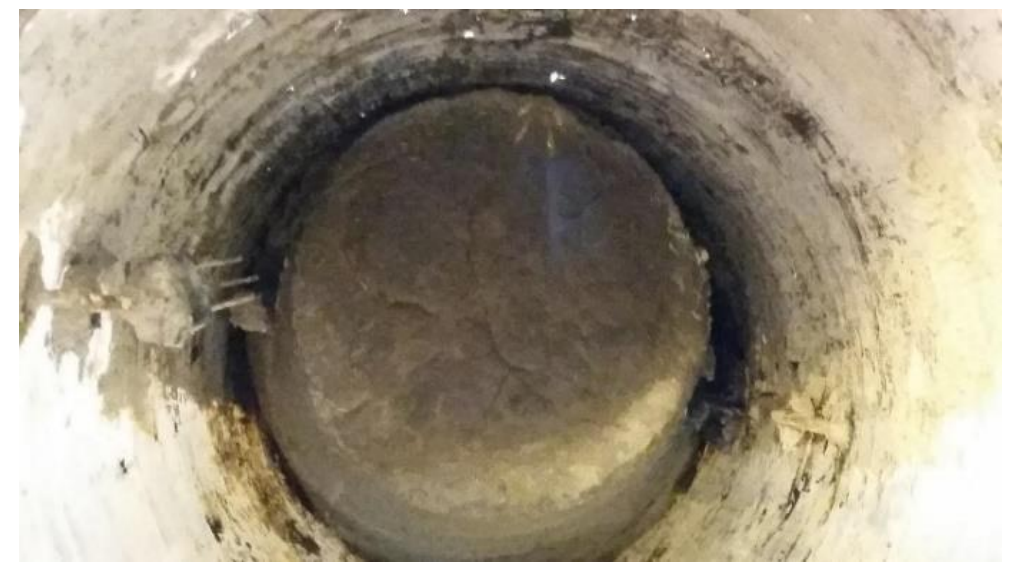

Figure 12 Photo showing sample consolidated and compressed laterally; flocculated FFT from Column 2 
Figures 13 present samples of photos taken during the self-weight consolidation laboratory testing for the meso-scale experiment.

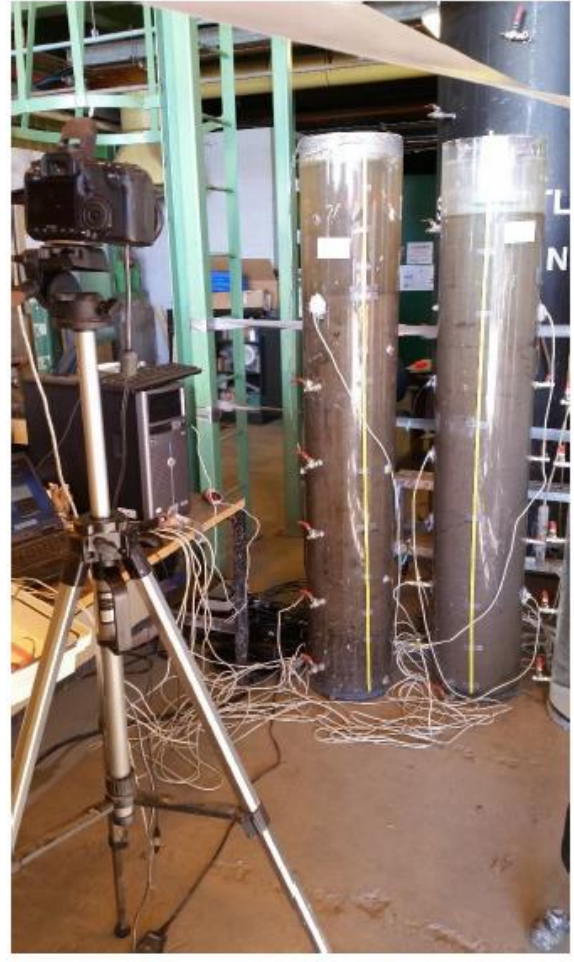

a)

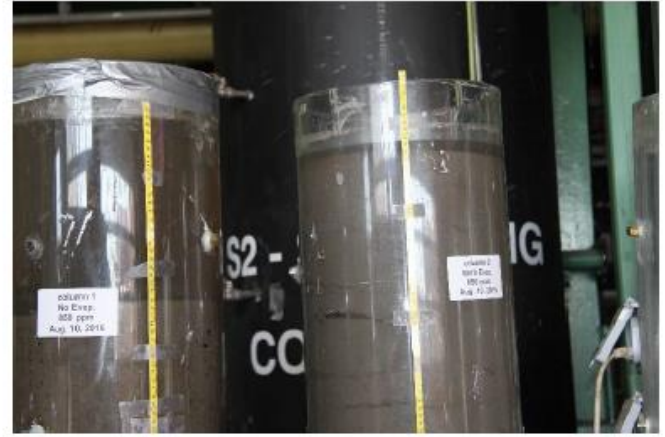

b)

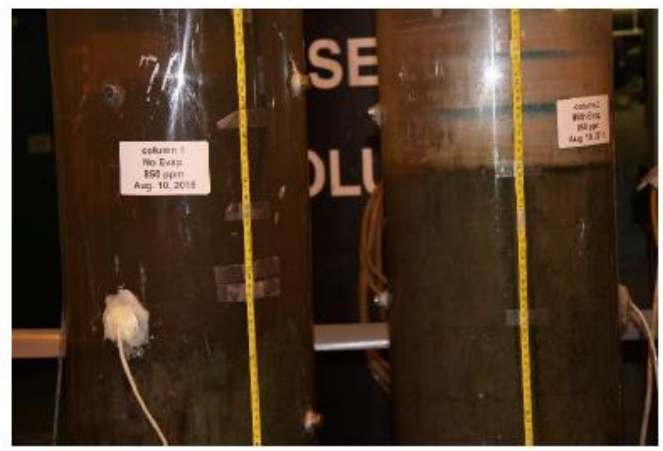

c)

Figure 13 Photos showing full-scale laboratory testing of the self-weight consolidation of flocculated FFT; (a) Full-scale photo of Column 1 and 2 testing set-up; (b) Closer look of Column 1 with covered top to prevent evaporation and Column 2 with no cover on the column; and, (c) Closer look of the collected water on Column 1 and no bleed water on Column 2

\section{Summary and conclusion}

Laboratory experimental tests were carried out to characterise and measure engineering properties of inline flocculated FFT. Meso-scale column tests were conducted to determine self-weight properties of polymer-amended tailings. The meso-scale columns were designed to mimic commercial-scale conditions. Detailed descriptions of the self-weight consolidation set-up preparation, design consideration, flocculant dosage used, and results obtained are presented and discussed. Results from the meso-scale consolidation test exhibited accelerated excess pore water pressure dissipation for the columns tested under design consideration that allowed evaporation and decantation scenario, followed by the columns tested under the evaporation-only conditions. Excess pore water pressures took longer to dissipate for the column tested under a no-evaporation condition compared to the other scenarios. In addition, there was not much difference between flocculant dosages used (i.e. between 650 and $850 \mathrm{ppm}$ ). Further investigation is needed to better understand the exhibited differences between the settling rate and total settlement of deposited tailings. These measured data will provide a basis to validate constitutive relations of flocculated FFT in stress-strain state in relation to self-weight consolidation under various environmental considerations. Furthermore, these properties are used in versatile numerical models that can analyse and calculate the properties of FFT deposits.

\section{$6 \quad$ Future work}

Further characterisation of the consolidated flocculated FFT is in progress to further understand the self-weight consolidation process of the material under investigation during the finalisation process of the meso-scale columns tests. The results will be analysed and reported once the entire research program is concluded. 


\section{Acknowledgement}

The authors thank the National Science and Engineering Research Council (NSERC) for their financial support of this research.

\section{References}

Beier, N, Alostaz, M \& Sego, D 2009, 'Natural dewatering strategies for oil sands fine tailings', in DC Sego, M Alostaz and NA Beier (eds), Proceedings of the 13th Annual Conference on Tailings and Mine Waste, pp. 845-858.

Dunmola, A, Dhadli, N, Freeman, G, Kolstad, D, Song, J, Fasking, T \& Langseth, J 2014, 'Geotechnical benefits of flocculation in dewatering oil sands mature fine tailings', Proceedings of the 66th Canadian Geotechnical Conference.

Fisseha, B, Bryan, R \& Simms, P 2010, 'Evaporation, unsaturated flow, and salt accumulation in multilayer deposits of a gold "paste" tailings', ASCE Journal of Geotechnical and Geoenvironmental Engineering, vol. 136, no. 12, pp. 1703-1712.

Fisseha, B, Wilson, GW \& Fredlund, DG 2017, 'Assessment of large-strain consolidation and shear strength of saturated/unsaturated fluid fine tailings', Proceedings of the 70th Canadian Geotechnical Conference.

Jeeravipoolvarn, S, Scott, JD \& Chalaturnyk, R 2010, 'Composite tailings made from inline thickened oil sands tailings', in DC Sego and NA Beier (eds), Proceedings of the 2nd International Oil Sands Tailings Conference, Oil Sands Tailings Research Facility, Devon.

Matthews, J, Dhadli, N, House, P \& Simms, P 2011, 'Field trials of thin-lift deposition of amended mature fine tailings at the Muskeg River Mine in Northern Alberta', in RJ Jewell and AB Fourie (eds), Proceedings of the 14th International Seminar on Paste and Thickened Tailings, Australian Centre for Geomechanics, Perth, pp. 271-280.

Mizani, S, He, X \& Simms, P 2013, 'Application of lubrication theory to modelling stack geometry of high density mine tailings', Journal of Non-Newtonian Fluid Mechanics, vol. 198, pp. 59-70.

Mizani, S 2017, Experimental Study and Surface Deposition Modelling of Amended Oil Sands Tailings Products, PhD Thesis, Carleton University, Ottawa.

Morgenstern, NR \& Scott, JD 1995, 'Geotechnics of fine tailings management', in YB Acar and DE Daniel (eds), Geoenvironment 2000: Characterization, Containment, Remediation, and Performance in Environmental Geotechnics, Geotechnical Special Publication 46, American Society of Civil Engineers, New York, pp. 1663-1683.

Oil Sands Tailings Research Facility 2017, Our Facility, Oil Sands Tailings Research Facility, Devon, viewed 14/02/2018, http://www.ostrf.com/facility

Pollock, GW 1988, Large Strain Consolidation of Oil Sand Tailings Sludge, MSc thesis, University of Alberta, Edmonton.

Qi, S, Simms, P \& Vanapalli, S 2017a, 'Piecewise-linear formulation of coupled large-strain consolidation and unsaturated flow. I: Model development and implementation', Journal of Geotechnical and Geoenvironmental Engineering, vol. 143, no. 7, pp. 04017019-1-04017019-12.

Qi, S, Simms, P, Vanapalli, S \& Soleimani, S 2017b, 'Piecewise-linear formulation of coupled large-strain consolidation and unsaturated flow. II: Testing and performance', Journal of Geotechnical and Geoenvironmental Engineering, vol. 143, no. 7, pp. 04017018-1-04017018-11.

Qi, S, Simms, P, Vanapalli, S \& Farzad, D 2016, 'A large strain consolidation-unsaturated flow model for tailings analysis: mutilayers', Proceedings of the 69th Canadian Geotechnical Conference.

Rozina, E, Mizani, S, Malek, M, Sanchez-Sardon, M \& Simms, P 2015, 'Dewatering in a laboratory simulation of a multilayer deposit of inline flocculated mature fine tailings', in RJ Jewell and AB Fourie (eds), Proceedings of the 18th International Seminar on Paste and Thickened Tailings, Australian Centre for Geomechanics, Perth, pp. 81-93.

Salfate, EB, Wilson, GW, Wijiewickreme, D \& Simms, P 2010, 'Predicting void ratio in surface deposited paste tailings', in AB Fourie and RJ Jewell (eds), Proceedings of the First International Seminar on the Reduction of Risk in the Management of Tailings and Mine Waste, Australian Centre for Geomechanics, Perth, pp. 473-485.

Simms, P, Dunmola, A, Fisseha, B, \& Bryan, R 2010, 'Generic modelling of desiccation for cyclic deposition of thickened tailings to maximize density and to minimize oxidation', in RJ Jewell and AB Fourie (eds), Proceedings of the 13th International Conference on Paste and Thickened Tailings, Australian Centre for Geomechanics, Perth, pp. 293-301.

Simms, P, Grabinsky MW, \& Zhan, G 2007, 'Modelling evaporation of paste tailings at the Bulyanhulu mine', Canadian Geotechnical Journal, vol. 44, no 12, pp. 1417-1432.

Simms, P, Soleimani, S, Mizani, S, Daliri, F, Dunmola, A, Rozina, E \& Innocent-Bernard, T 2017, 'Cracking, salinity and evaporation in mesoscale experiments on three types of tailings', Environmental Geotechnics, pp. 1-15, https://doi.org/10.1680 /jenge.16.00026

Soleimani, S, Simms, P, Dunmola, A, Freeman, G \& Wilson, GW 2014, 'Desiccation and consolidation in thin-lift deposition of polymer amended mature fine tailings', in RJ Jewell, AB Fourie, PS Wells and D van Zyl (eds), Proceedings of the 17th International Seminar on Paste and Thickened Tailings, InfoMine Inc., Vancouver, pp. 307-322.

Wells, PS 2011, 'Long-term in-situ behaviour of oil sands fine tailings in Suncor's Pond 1A', Proceedings of the 15th International Conference on Tailings and Mine Waste, Norman B. Keevil Institute of Mining Engineering, Vancouver. 